\title{
THE EFFECT OF INTRAVENOUS INFUSION OF HYPERTONIC SALINE ON THE INTRA-OCULAR PRESSURE*
}

BY

\author{
H. Davson AND T. L. Thomassen \\ From the Ophthalmological Research Unit, Medical Research Council. \\ Institute of Ophthalmology, London
}

THE exchange of water between blood and eye fluids is very rapid (Kinsey, Grant, and Cogan, 1942) in comparison with the migration of sodium chloride across the blood aqueous barrier. Consequently, on making the blood hypertonic by the intravenous injection of sodium chloride, water should be withdrawn from the eye, and the intra-ocular pressure lowered. Qualitatively, such an effect has been described (Duke-Elder, 1926), and the observation has been cited as evidence in favour of the dialysis theory of the formation of the intra-ocular fluid, although an alternative interpretation was placed on the results by Robertson (1937). For

TABLE

Effect of Intravenous Infusion of $\mathbf{4 . 5}$ per cent. $\mathrm{NaCl}$ Solution on Intra-Ocular Pressure

\begin{tabular}{|c|c|c|c|c|c|c|}
\hline \multirow{2}{*}{$\begin{array}{c}\text { No. of } \\
\text { Experiments }\end{array}$} & \multicolumn{4}{|c|}{$\begin{array}{l}\text { Concentration of } \mathrm{Na} \\
\left(\mathrm{mmols} / \mathrm{kg} \cdot \mathrm{H}_{2} \mathrm{O}\right)\end{array}$} & \multirow{2}{*}{$\begin{array}{l}\text { Fall in pressure } \\
\quad(\mathrm{mm} . \mathrm{Hg})\end{array}$} & \multirow{2}{*}{$\begin{array}{c}\text { Rate of } \\
\text { injection } \\
\text { (ml./min.) }\end{array}$} \\
\hline & $\mathrm{B}_{1}$ & $\mathbf{B}_{\mathbf{2}}$ & $\mathrm{Aq}$ & $\mathbf{r}$ & & \\
\hline $\begin{array}{r}1 \\
2 \\
3 \\
4 \\
5 \\
6 \\
7 \\
8 \\
9 \\
10 \\
11\end{array}$ & $\begin{array}{l}158 \\
158 \\
160 \\
165 \\
157 \\
159 \\
162 \\
158 \\
157 \\
161 \\
160\end{array}$ & $\begin{array}{l}173 \\
188 \\
170 \\
198 \\
175 \\
191 \\
174 \\
174 \\
171 \\
178 \\
170\end{array}$ & $\begin{array}{l}156 \\
163 \\
153 \\
-151 \\
-\overline{163} \\
161 \\
154 \\
156 \\
156\end{array}$ & $\begin{array}{l}1 \cdot 11 \\
1 \cdot 15 \\
1 \cdot 11 \\
\overline{1 \cdot 15} \\
\overline{1 \cdot 07} \\
1 \cdot 08 \\
1 \cdot 11 \\
1 \cdot 14 \\
1 \cdot 09\end{array}$ & $\begin{array}{l}7 \cdot 5 \\
9 \\
3 \cdot 5 \\
12 \cdot 5 \\
2 \\
6 \\
7 \cdot 5 \\
2 \\
8 \\
2 \\
6 \cdot 5\end{array}$ & $\begin{array}{l}2 \cdot 4 \\
2 \cdot 8 \\
1 \cdot 4 \\
1 \cdot 5 \\
1 \cdot 4 \\
2 \cdot 9 \\
1 \cdot 6 \\
2 \cdot 2 \\
1 \cdot 7 \\
2 \cdot 4 \\
1 \cdot 7\end{array}$ \\
\hline Meàn & 159 & 178 & 157 & $1 \cdot 11$ & 6 & 2 \\
\hline
\end{tabular}

$B_{1}, B_{2}$ blood samples taken at beginning and end of experiment.

$r=$ ratio (Concentration of Sodium in Plasma/Concentration of Sodium in Aqueous) at end of experiment.

a full understanding of the effects of hypertonic solutions on the intra-ocular pressure, however, it is not sufficient to give a single massive injection and observe the results; interpretation of any

\footnotetext{
* Received for publication February 10, 1950.
} 
effects observed will be obscured by ignorance of the actual concentration of salt in the blood at any moment, owing to its elimination by the kidneys. In the present work, the concentration of $\mathrm{NaCl}$ in the blood has been raised gradually and continuously by an intravenous drip technique, and its value estimated at appropriate intervals; the concentration in the aqueous humour was determined, moreover, at the end of the period of measurement.

\section{Experimental Procedure}

Cats were anaesthetized with nembutal and one femoral artery and vein cannulated. After inserting the manometer needle into one eye, and waiting for the intra-ocular pressure to settle down to a reasonably constant value, 4.5 per cent. sodium chloride was infused into the femoral vein at a steady and predetermined rate $(1.6$ to $2.5 \mathrm{ml}$./min.). Blood samples were withdrawn from the femoral artery before and during the infusing of sodium chloride; at the end of the experiment, aqueous humour was withdrawn from the other eye at the same time as the sample of blood. Sodium was determined by methods already described (Davson, 1939); intra-ocular pressure by the manometer recently described (Davson and Purvis, 1950).

\section{Results}

In general, hypertonic saline produced a slow decline of intra-ocular pressure varying in extent from 2 to $12.5 \mathrm{~mm}$. $\mathrm{Hg}$, with a mean value of 6 (see Table).

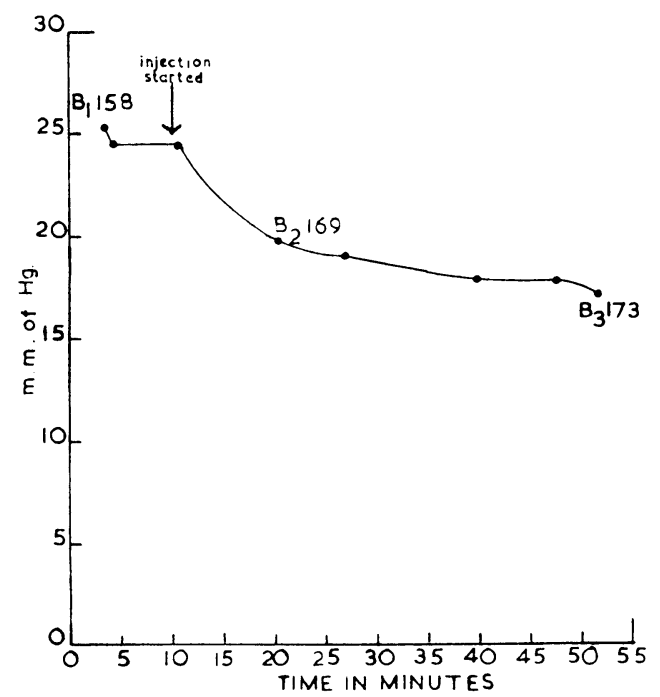

FIG. 1. Effect of intravenous infusion of hypertonic saline on intra-ocular pressure. Figures on curve indicate concentration of sodium in plasma in mmols $/ \mathrm{kg}$. $\mathrm{H}_{2} \mathrm{O}$.
Fig. 1 illustrates a typical curve, whilst Fig. 2 is a mean curve computed from eleven experi. ments; it will be seen that the rate of fall in pressure slackens off very considerably, so that after about $20 \mathrm{~min}$. of injection the pressure becomes virtually constant. Fig. 3 shows the results of an experiment in which the infusion ceased after about 30 min., but in which the intra-ocular pressure was re corded for a further $30 \mathrm{~min}$. It will be noted that the pressure remained low and showed no sign of returning to its original value. This is typical of practically all the results in which the intra-ocular pressure has been followed for some time after the infusion ceased. The figures on the curves indicate the concentration of sodium in the plasma in mmols $/ \mathrm{kg}$. $\mathrm{H}_{2} \mathrm{O}$; the results, and others not presented here, show that the concentration of sodium rises continuously during the infusion. The relative concentra. tions of sodium in blood and aqueous at the end of the experiment indicated, moreover, that there was a considerable excess of sodium in the blood over that in the aqueous. Thus the normal ratio of the concentrations is about 1.04 , whereas the ratio was never less than 1.07 , 
and had an average value of 1.11. As a control, several experiments were carried out with isotonic sodium chloride; in general this resulted in a small rise in pressure, although in two experiments there was no change. The rise was probably due to the increased blood volume (Duke-Elder, 1926).

\section{Discussion}

The results leave one in little doubt as to the possibility of modifying the intra-ocular pressure by purely osmotic means; some quantitative considerations reveal, however, that the final

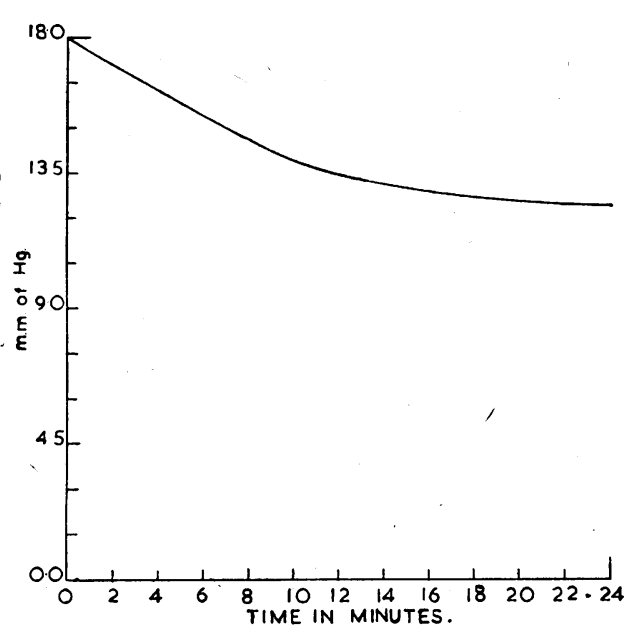

FIG. 2.-Effect of intravenous infusion of hypertonic saline on intra-ocular pressure, mean curve for 11 experiments. result on the intra-ocular pressure is determined by a balance of osmotic withdrawal of fluid and secretory formation. Thus, on a dialysis or ultrafiltration theory, the only force available to drive fluid into the intra-ocular cavities is the difference between the intra-ocular capillary pressure and the colloid osmotic pressure of the plasma proteins. The maximal capillary pressure is unlikely to be more than $60 \mathrm{~mm}$. Hg, whilst the colloid osmotic pressure is in the region of $25 \mathrm{~mm}$. $\mathrm{Hg}$; consequently, the maximal driving force is of the order of $35 \mathrm{~mm}$. $\mathrm{Hg}$. In the experiment illustrated in Fig. 1, the sodium ratio was 1.11 , whilst the pressure was constant at some 17 . to $18 \mathrm{~mm}$. $\mathrm{Hg}$, so that the difference of osmotic pressure draining water out of the eye was in the region of $380 \mathrm{~mm}$. $\mathrm{Hg}$. On the basis of the dialysis or ultra-filtration theory, therefore, the intra-ocular pressure should have been strongly negative. If, however, we assume a continuous formation of intra-ocular fluid by a secretory process, the withdrawal of fluid by osmotic means need not necessarily reduce the intra-ocular pressure by a large amount, the osmotic withdrawal being in some measure compensated by the continuous inward flow. Thus it is now well established that there is normally a continuous flow of fluid into the intra-ocular cavities, inwards by way of the ciliary body, and outwards at the angle of the anterior chamber. The intra-ocular pressure represents the balance struck between inward and outward 
flow. If an artificial outward flow is induced by the osmotic withdrawal of water, this effect will be balanced partly, if not completely, by the cessation of the normal drainage process; it is possible also, but not proved, that the fall of intra-ocular pressure, resulting from too great a loss of fluid, may be compensated by an increased rate of formation. The achievement of a steady state as indicated in Fig. 1, is therefore intelligible. We may note also that a further stabilization factor is the tendency of the concentration of sodium in blood and aqueous to become equal as a result

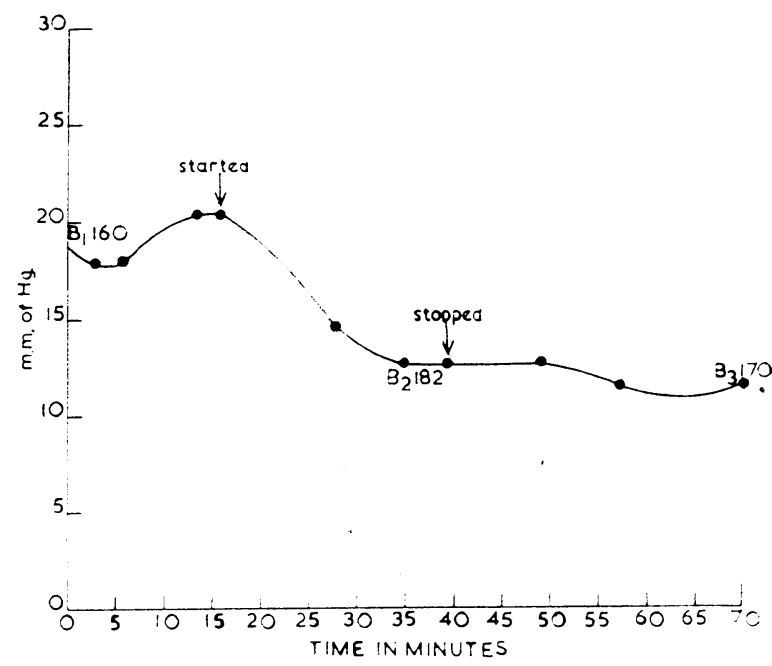

FIG. 3-Effect of intravenous infusion of hypertonic saline on intra-ocular pressure, showing course of intraocular pressure after cessation of infusion.

of withdrawal of water from the aqueous humour. The results show, however, that they never did become constant, so that in our experiments there must always have been an osmotic withdrawal.

The clinical use of a single massive injection of hypertonic saline to reduce the intra-ocular pressure probably has its basis in the small fall in the intra-ocular pressure recorded here, although other factors may play a part. In several experiments on humans carried out during this work, chemical analysis revealed a definite increase in blood sodium (from 1 to 4 per cent.) after an injection of 20 to $30 \mathrm{ml}$. 30 per cent. $\mathrm{NaCl}$. The intraocular pressure fell on the average by $8 \mathrm{~mm}$. $\mathrm{Hg}$ Schiötz for about 1 hour. Simultaneous observations of the aqueous veins, 


\section{Intra-Ocular Presśure Changes \\ EXPERIMENTALLY INDUCED}

however, failed to reveal any striking change; it was thought that the osmotic drainage would cut down the-normal drainage by these channels, but no evidence in the form of an unequivocal decrease in flow of aqueous was obtained.

\section{Summary}

Continuous intravenous infusion of hypertonic $\mathrm{NaCl}$ caused a small fall in the intra-ocular pressure, after which the latter was generally stabilized. Chemical analysis revealed that during the whole of the experiments there was a considerable excess of sodium in the plasma over that in the aqueous humour, the level in the blood rising continuously during the infusion.

\section{REFERENCES}

Davson, H. (1939). J. Physiol., 96, 194.

- and PURVIS, C. (1950). British Journal of Ophthalmology, 34, 351.

DUKE-ELDER, W. S. (1926). Ibid., 10, 1.

Kinsey, V. E., Grant,-W. M., and Cogan, D. G. (1942). Arch. Ophthal., Chicago, 27, 242.

RoBertSon, J. D. (1937). British Journal of Ophthalmology, 21, 401. 